\title{
Social Network Analysis: An Introduction ${ }^{1}$
}

\author{
Alexandra Marin and Barry Wellman \\ Department of Sociology, University of Toronto
}

May 26, 2009

Forthcoming in Handbook of Social Network Analysis. Edited by Peter Carrington and John Scott. London: Sage, 2009

Social network analysis takes as its starting point the premise that social life is created primarily and most importantly by relations and the patterns formed by these relations. Social networks are formally defined as a set of nodes (or network members) that are tied by one or more types of relations (Wasserman and Faust, 1994). Because network analysts take these networks as the primary building blocks of the social world, they not only collect unique types of data, they begin their analyses from a fundamentally different perspective than that adopted by individualist or attribute-based social science.

For example, a conventional approach to understanding high-innovation regions such as Silicon Valley would focus on the high levels of education and expertise common in the local labour market. Education and expertise are characteristics of the relevant actors. By contrast, a network analytic approach to understanding the same phenomenon would draw attention to the ways in which mobility between educational institutions and multiple employers has created connections between organizations (Fleming et al., forthcoming). Thus, people moving from one organization to another bring their ideas, expertise, and tacit knowledge with them. They also bring with them the connections they have made to coworkers, some of whom have moved on to new organizations themselves. This pattern of connections between organizations, in which each organization is tied through its employees to multiple other organizations, allows each to draw on diverse sources of knowledge. Since combining previously disconnected ideas is the heart of innovation and a useful problem-solving strategy (Hargadon and Sutton, 1997), this pattern of connections - not just the human capital of individual actors - leads to accelerating rates of innovation in the sectors and regions where it occurs (Fleming et al., forthcoming).

In this chapter, we begin by discussing issues involved in defining social networks, and then go on to describe three principles implicit in the social network perspective. We explain how these principles set network analysis apart from attribute- or group-based perspectives. In Section II we summarize the theoretical roots of network analysis and the current state of the field, while in Section III we discuss theoretical approaches to asking and answering questions using a network analytic approach. In Section IV we turn our attention to social network methods - which we see as a set of tools for applying network theory rather than as the defining feature of network analysis. In our concluding section we argue that social network analysis is best understood as a perspective within the social sciences and not as a method or narrowly-defined theory.

\footnotetext{
${ }^{1}$ We thank Julie Bowring, Jessica Collins, Robert Di Pede, Sherri Klassen, and Paromita Sanyal for their comments on this chapter and Julia Chae, Stephen Di Pede, Christine Ensslen, Sinye Tang, Yu Janice Zhang and Natalie Zinko for editorial assistance.
} 


\section{What is a Social Network?}

A social network is a set of socially-relevant nodes connected by one or more relations. Nodes, or network members, are the units that are connected by the relations whose patterns we study. These units are most commonly persons or organizations, but in principle any units that can be connected to other units can be studied as nodes. These include web pages (Watts, 1999), journal articles (White, Wellman and Nazer, 2004), countries, neighbourhoods, departments within organizations (Quan-Haase and Wellman, 2006), or positions (Boorman and White, 1976; White et al., 1976).

Defining which nodes to include in a network analysis often poses an early challenge. A scholar might know that she wishes to analyze medical researchers studying a heart disease. However, knowing which individuals to consider as researchers in this field can be tricky, especially because many network analysts avoid group-based approaches to understanding the social world.

Laumann et al. (1983) identify three approaches to addressing this boundary specification problem: A position-based approach considers those actors who are members of an organization or hold particular formally-defined positions to be network members and all others would be excluded. In the example listed above, network members could be researchers employed in hospital cardiology departments or members of a professional association for cardiologists. An event-based approach to defining the boundaries of the network looks instead at who had participated in key events believed to define the population. For example, this might include researchers who had attended at least two cardiology conferences in the past three years. A relation-based approach begins with a small set of nodes deemed to be within the population of interest and then expands to include others sharing particular types of relations with those seed nodes as well as with any nodes previously added. For example, a relation-based approach might begin with researchers publishing in a key cardiology journal and include their co-authors and collaborators, and their co-authors and collaborators, etc. This relation-based approach is particularly common in the study of egocentric networks, which we discuss below (see also Hanneman and Riddle, this volume and Chua, Madej and Wellman, this volume).

These three approaches are not mutually exclusive, and studies will commonly use a combination of more than one approach to define network boundaries. For example, they might include only researchers who work in cardiology departments and attend cardiology conferences.

After researchers have identified network members, they must identify the relations between these nodes. These could include collaborations, friendships, trade ties, web links, citations, resource flows, information flows, exchanges of social support, or any other possible connection between these particular units (Wasserman and Faust, 1994). Borgatti et al. (2009) identify four broad categories of relations: similarities, social relations, interactions, and flows.

Similarities occur when two nodes share the kinds of attributes frequently studied in variablebased approaches, such as demographic characteristics, attitudes, locations, or group memberships. Group memberships (particularly co-memberships and interlocking memberships) are the only similarities frequently treated as relations by network analysts. For example, network analysts have examined the structure of industries by studying networks created by interlocking directorates (Mizruchi and Stearns, 1988; Mintz and Schwartz, 1985). 
Social relations include kinship or other types of commonly-defined role relations (e.g., friend, student); affective ties, which are based on network members' feelings for one another (e.g., liking, disliking); or cognitive awareness (e.g., knowing). These are among the ties most commonly studied by personal community analysts. For example, Killworth et al. (1990) study the network of people "known" by respondents, and Casciaro et al. (1999) study how affective ties (liking) predict cognitive perceptions of network forms.

Interactions refer to behaviour-based ties such as speaking with, helping, or inviting into one's home. Interactions usually occur in the context of social relations, and interaction-based and affective-based measures are frequently used as proxies for one another. For example, researchers may measure discussion networks as proxies for core support networks (Marsden, 1987; McPherson et al., 2006).

Flows are relations based on exchanges or transfers between nodes. These may include relations in which resources, information, or influence flow through networks. Like interactions, flowbased relations often occur within other social relations, and researchers frequently assume or study their co-existence. For example, Wellman and Wortley (1990) show how social relation ties such as kinship and friendship affect the exchange of different kinds of support and companionship.

\section{Guiding Principles of Network Analysis}

Taking social relations seriously calls for more than knowing how to measure some characteristics of networks, such as the density of their interconnections. It requires a set of assumptions about how best to describe and explain the social phenomena of interest. Network explanations do not assume that environments, attributes or circumstances affect actors independently. Moreover, they do not assume the existence of uniformly cohesive and discretely-bounded groups. Finally, network analysis takes context so seriously that relations themselves are often analyzed in the context of other relations.

\section{Relations, Not Attributes}

Individuals (and organizations, countries, web pages, etc.) indisputably possess particular attributes. To study the effects of attributes such as race, gender or education - which are inherently contained within and not between actors - researchers sort individuals based on their attributes and determine which outcomes are disproportionately common to individuals with particular attributes. This endeavour treats causation as something that comes from within individuals, with common attributes acting independently on individuals to produce similar outcomes.

By contrast, social network analysts argue that causation is not located in the individual, but in the social structure. While people with similar attributes may behave similarly, explaining these similarities by pointing to common attributes misses the reality that individuals with common attributes often occupy similar positions in the social structure. That is, people with similar attributes frequently have similar social network positions. Their similar outcomes are caused by the constraints, opportunities, and perceptions created by these similar network positions. By studying behaviour as embedded in social networks, social scientists are able to explain 
macro-level patterns not simply as a large number of people acting similarly because they are similar, but as a large number of people acting on one another to shape one another's actions in ways that create particular outcomes. For example, researchers using an attribute-based approach might find that tough economic times make Mary, John and Susan each cut back on spending. In each case, Mary, John and Susan are independently - without regard to one another or to other people - acted upon by economic conditions and by attributes such as their net worth, financial savvy or internalized norms of frugality. By contrast, social network analysts would argue that understanding how this happens requires understanding how John, Mary and Susan's relationships with each other - and with others - affect their views of the economy, their ideas about reasonable spending, and their opportunities to save or to splurge. For example, financial knowledge or advice can come from network members (Chang, 2005), and network-based reference groups shape norms of saving or splurging (Zelizer, 1994). While economic choices may be correlated with attributes, this is because of network positions. In addition to being a more realistic model of causation, a network-based explanation is better able to explain how feedback loops can cause an epidemic of frugality, infecting even those with secure incomes and contributing further to economic troubles in societies.

\section{Networks, Not Groups}

While researchers using a network analytic approach must be concerned with defining the boundaries of the networks they study, they do not treat network embeddedness as binary, and they do not treat nodes as belonging only to sets of mutually-exclusive groups. It is too easy an oversimplification for researchers seeking to understand the effects of opportunities and constraints afforded to people in various positions to operationalize these positions by dividing research subjects into discrete groups, such as employees in different departments, residents of different city districts, or members of different school clubs. Treating these group memberships as having discretely bounded or mutually exclusive memberships makes invisible the importance of differing levels of group membership, membership in multiple groups, and cross-cutting ties between groups.

Studying group membership as having a uniform influence on members only makes sense if membership itself is uniform: if every group member shares the same relation to the group. This is rarely the case. Even where something that would be recognized as a "group" exists, some members are more or less committed, more or less tied to other group members, more or less identified with the group, or more or less recognized by others as co-members of the group. For example, people affiliated with universities are sorted into departments, which could be treated as groups. However, to treat group membership as binary and thus uniform ignores distinctions between full-time, adjunct, cross-appointed, visiting, and emeritus faculty, to say nothing of students, staff, and alumni. While one might argue that the department qua department has particular interests, the extent to which these interests are shared by department members and the extent to which department members influence one another's understandings of their own interests will vary.

A network approach to studying university departments would look instead at the strength and nature of connections of department members: the proportion of the individual's courses that are taught within a department, the level of funding and resources that flow from department to faculty member, the frequency of attendance at departmental talks, and the frequency of socializing with other members. Examining "groups" in this way has three advantages. First, it 
allows researchers to think of individuals as embedded in groups to varying degrees and thus differentially subject to the opportunities, constraints and influences created by group membership. Second, it allows researchers to examine variations in group structure, determining which groups are more or less cohesive, which are clearly-bounded, and which are more permeable. Such a strategy also allows network analysts to define groups empirically rather than a priori. Third, leaving open the questions of cohesion and boundary strength allows network researchers to move beyond studying clearly identifiable groups to studying sets of people that would be less easily identifiable as groups but that nonetheless structure social relations - such as gatherings of old-timers or newcomers at a windsurfing beach (Freeman et al., 1989). Approaches that assume mutually-exclusive group memberships preclude the study of patterns of multiple group membership or ties to multiple groups. Yet, multiple group memberships are the basis of social structure, creating bridges between some groups and just as significantly, not creating bridges between others (Blau, 1994; Breiger, 1974; Feld, 1981). Because people exist at the intersection of groups, memberships in multiple groups interact. They exacerbate or mitigate opportunities, constraints and influences offered by single group memberships, and influence the identities of group members. Thus, neglecting varying levels of overlap between social circles precludes the study of the social processes that knit otherwise atomized individuals into a society (Simmel, 1922 [1955]).

\section{Relations in a Relational Context}

Social network analysts study patterns of relations, not just relations between pairs. This means that while relations are measured as existing between pairs of nodes, understanding the effect and meaning of a tie between two nodes requires taking into account the broader patterns of ties within the network (Barnes, 1972). For example, while individual ties provide social support and companionship, the amount of support provided by one person to another is affected by the extent to which support network members know one another (Wellman and Frank, 2001). The nature of relationships between two people may also vary based on their relations with others. For example, understanding relations of support, jealousy, and competition between siblings requires understanding and taking into account the relationship of each to their parents. Parentchild relationships are similarly affected by the relationship each has with the other parent (Wellman and Frank, 2001). Thus, assuming that each pair acts independently hides network processes that are created by larger patterns in the network. For example, bridging is a structural condition where the tie creates a connection between previously unconnected portions of a network. A relationship between Romeo and Juliet constitutes a bridge between the Capulets and Montagues. To identify the tie as bridging, we must know the network of Verona elites well enough to know that the Capulets and Montagues are otherwise unconnected.

\section{The Origins and Current State of Social Network Analysis}

\section{Simmelian Roots}

The primacy of relations over atomized units is an idea much older than the field that has come to be known as network analysis (see Freeman, this volume). Network theorists have found examples of this idea in the work of influential thinkers from Heraclities to Einstein and from such giants of sociological theory such as Marx, Durkheim, Weber, Goffman and even Parsons (Emirbayer, 1997) - a theorist often associated with the norm-based approach with which network analysis is frequently contrasted (Granovetter, 1985; Wellman, 1988). 
The primacy of relations is most explicit in the work of Georg Simmel, whose theoretical writings inspired and anticipated major empirical findings in network analysis. Simmel clearly articulates the premise that social ties are primary. Instead of viewing things as isolated units, they are better understood as being at the intersection of particular relations and as deriving their defining characteristics from the intersection of these relations. He argues that society itself is nothing more than a web of relations. There is no "society" interactions:

The significance of these interactions among men lies in the fact that it is because of them that the individuals, in whom these driving impulses and purposes are lodged, form a unity, that is, a society. For unity in the empirical sense of the word is nothing but the interaction of elements. An organic body is a unity because its organs maintain a more intimate exchange of their energies with each other than with any other organism; a state is a unity because its citizens show similar mutual effects. (Simmel, 1908 [1971], p. 23)

Here, Simmel argues against understanding society as a mass of individuals who each react independently to circumstances based on their individual tastes, proclivities, and beliefs and who create new circumstances only by the simple aggregation of their actions. He argues we should focus instead on the emergent consequences of the interaction of individual actions:

A collection of human beings does not become a society because each of them has an objectively determined or subjectively impelling life-content. It becomes a society only when the vitality of these contents attains the form of reciprocal influence; only when one individual has an effect, immediate or mediate, upon another, is mere spatial aggregation or temporal succession transformed into society. (Simmel, 1908 [1971], pp. 24-25)

Based on his belief that the social world is found in interactions rather than in an aggregation of individuals, Simmel argued that the primary work of sociologists is to study patterns among these interactions - which he called forms - rather than to study the individual motives, emotions, thoughts, feelings, and beliefs - which he called content. Similar forms can exist and function similarly in diverse content areas, and different forms can emerge within any single content area. Therefore, Simmel argued, sociologists' study of form and content must remain separate. Only by studying similar forms across diverse contents can people truly understand how these forms function as forms and separate the effects of forms from the effects of contents. While a similar argument holds for the study of contents - they can be fully understood only by studying their manifestations in diverse forms - Simmel argued that the sociologist's role is to focus on form because only forms are "purely social," unlike contents which frequently exist as individual-level characteristics (Simmel, 1908 [1971]).

Although Simmel developed theories of many types of forms and the consequences of various forms across contents, he did not formalize his theories mathematically as many network analysts do today. However, he did recognize the inherently mathematical logic of his theories. He used geometric metaphors in his writing, and he compared the study of forms to geometricians' ability to analyze pure forms apart from their real-world manifestations (Simmel, 1908 [1971], pp. 24-25). His influence is apparent in much subsequent network analytic work, such as formalistic "blockmodelling" described below (White et al., 1976; Boorman and White, 1976 ) and Burt's substantive analysis $(1992,2005)$ of how individuals benefit by knowing two 
people unknown to each other.

\section{Current State: Association, Grants and Journals}

Today, social network analysis has become an interdisciplinary area of study, with its own professional association, annual conference, and multiple journals. The International Network for Social Network Analysts (INSNA), founded by Barry Wellman in 1977 has grown from 175 founding members to more than 1,200 members in February 2009. While sociologists form a plurality of members, the network also includes researchers from anthropology, communications, computer science, education, economics, management science, medicine, political science, public health, psychology, and other disciplines. INSNA's annual conference, the International Sunbelt Social Network Conference, attracts more than 500 people each year, to sites rotating in a three year cycle between the east and west coasts of North America and Europe.

Social network analysis is a thriving research area. Between 1998 and 2007, network-based projects accounted for the fourth largest share of grants dispensed by the Social Science Research Council of Canada, and was the area receiving the largest per-project grants (Klassen, 2008). Research applying a social network perspective appears in major generalist social science journals such as the American Journal of Sociology, American Sociological Review, Social Forces, Human Organization, and Administrative Science Quarterly as well as specialized journals, such as City and Community, Work and Occupations, and Information, Communication and Society. Three peer-reviewed journals publish social network research exclusively: Social Networks (INSNA's flagship journal), Connections (an INSNA journal publishing short, timely papers), and The Journal of Social Structure, published online.

\section{Applying a Network Perspective}

We have shown thus far that network analysts take patterns of relations between nodes as the primary unit for sociological theorizing and research. In this section we describe the ways in which network analysts use this perspective to develop theory, including those analysts that focus exclusively on patterns of relations themselves and those that seek to address substantive issues.

\section{Formalist Theories}

Formalist theories are concerned primarily with describing the mathematical form of social networks (see Scott, this volume). These theories study the effects of forms, insofar as they are effects on the form itself, and the causes of these forms, insofar as they are structural. For example, when networks are composed of clusters of densely connected nodes with many ties within clusters and just a small number of ties between clusters, the result is a network in which short paths are available between most pairs of nodes (Watts, 1999).

Because these theories are concerned primarily with pure form - in the mathematical, platonic sense - of networks, they can be studied without the need for empirical data. Mathematical modelling and computer simulations can be used to create networks that allow researchers to observe unfolding patterns of relations that result from particular rules of tie formation or dissolution. For example, Barabasi and Albert (1999) simulated networks that were continually 
joined by new nodes. As they joined, nodes formed ties to existing nodes, particularly to alreadypopular existing nodes. Based on these simulations they showed that this form of preferential attachment creates a Matthew Effect ("For to everyone who has, more will be given," Matthew 25: 29; see also Merton, 1968), magnifying popularity gaps and creating networks with powerlaw distributions. That is, it creates networks where a small number of nodes have huge numbers of ties, while the vast majority of nodes have only a few.

Recently, formalist-based research has received popular exposure in trade books such as $\mathrm{Six}$ Degrees (Watts, 2003), Linked (Barabasi, 2002), and Nexus (Buchanon, 2002), partly because the approach has interesting real-world applications. For example, the concept of preferential attachment is based on the empirical reality that people meet people through other people. The more people you know, the more people can introduce you to others. Small world networks also resonate well with the public imagination. The most well known example of a small world network is a network formed by co-appearances in movies and television shows. This is a clustered network with clusters created both by career timing (Rudolph Valentino and Dakota Fanning are unlikely to have ever been co-stars), and by actors' specialization within genres. For example there is a cluster of actors frequently co-starring in romantic comedies: Jennifer Aniston, Hugh Grant, Meg Ryan, Tom Hanks, and Julia Roberts. Yet, genre-based clusters are inter-connected thanks to genre-hopping actors. For example, Tom Hanks links actors appearing in romantic comedies to those appearing in children's films (Toy Story, Polar Express), dramas (Philadelphia), comedies (Turner and Hooch), and film adaptations of pulp fiction conspiracy theories (The Da Vinci Code, Angels and Demons). Genre-crossing actors, such as Tom Hanks, Kevin Bacon and many lesser-known genre crossers, make possible the well known game: "Six Degrees of Kevin Bacon." While identifying the shortest path to Kevin Bacon may be a challenge (Watts et al., 2002), a path no longer than four degrees exists for the large majority of those appearing on television and in film (Watts, 1999).

\section{Structuralist Theories}

Structuralist theories are concerned with how patterns of relations can shed light on substantive topics within their disciplines. Structuralists study such diverse subjects as health (Lin and Ensel, 1989; Pescosolido, 1992; Cohen et al., 1997; S. Cohen et al., 2001), work (Burt, 1992; Podolny and Baron, 1997; Ibarra, 1993), and community (Fischer, 1982a; Wellman and Wortley, 1990). Structuralists take at least four different approaches to applying the mantra that relations matter.

\section{Defining Key Concepts in Network Terms}

One approach to applying a network perspective to a substantive area is to take a key concept within that area and define it in network terms. Researchers adopting this approach examine how new understandings of the key concept reframe longstanding debates and call widely-accepted findings into doubt. For example, Wellman argued that communities are not geographic areas providing support and services, but people providing support and services to those to whom they are connected. By thinking of communities as "personal", meaning that every person's community uniquely consists of the people to whom he is connected, Wellman transformed understandings of how modernity and urban living affect interaction and support (Wellman, 1979; Wellman and Wortley, 1990). This work set the agenda for debates that would follow surrounding how social support networks are changing (Fischer, 1982a; Grossetti, 2005; Hennig, 2007), and the effects of new technology on community (Wellman et al., 2006; Boase and 
Wellman, 2006; Hampton, 2007; Stern, 2008). See Chua, Madej and Wellman, this volume.

\section{Testing an Existing Theory}

Closely related to the approach of redefining a single concept, some researchers start from an existing sociological theory. By thinking of relation-based understandings of the theory and testing the resulting hypotheses, these researchers apply a network approach to a theory that may previously have been studied using attribute- or group-based approaches. For example, Wilson's $(1978,1987)$ theory of the underclass suggests that as poor African Americans have come increasingly to live in high-poverty neighbourhoods, they have lost connections to people who provide ties to the labour market. Their social isolation contributes to difficulties in finding work, and it hinders social mobility.

Although Wilson's argument speaks of network connections, the evidence presented is still group-based, treating neighbourhoods as monoliths that are connected - or not connected - to the labour market by virtue of the neighbourhood's class composition. Further, by focussing on within-neighbourhood ties, the theory neglects the possibility of out-group ties providing connections to the labour market. However, the story may be more complex. Fernandez (1992) finds that the urban poor do have out-group ties to people committed to labour market participation, while Smith (2005) further finds that what African-American urban poor lack are ties to people in the labour market who are willing to offer assistance in finding jobs. By looking at real patterns of relations rather than assuming a lack of relations based on a perceived lack of opportunity, such research creates a stronger link between theory and data. The original theory like many social theories that are studied nonetheless from attribute-based or group-based perspectives - is about patterns of relations. Therefore, the theory can be more validly tested using data on relations than data on neighbourhood characteristics.

\section{Looking at network causes of phenomenon of interest}

Researchers taking this approach ask what kinds of social networks lead to particular outcomes. These outcomes may include finding a job (Granovetter, 1973, 1974) or promotion (Burt, 1997, 1998; Podolny and Baron, 1997; Ibarra, 1997), catching a cold (Cohen et al., 1997; S. Cohen et al., 2001), having a good idea (Burt, 2004), being sexy (Martin, 2005), or knowing about different kinds of culture (Erickson, 1996).

Network-based explanations of substantive outcomes are fundamentally different from explanations that rely on individual-level or group attributes. Social network analysts often have little tolerance for norm-based explanations, norms being precisely the kind of content that Simmel argued was outside the domain of social explanations. Moreover, when causal forces are presumed to be internal or possessed by individuals, the mechanisms frequently are internalized norms or atomized rational actors (Granovetter, 1985). Social network analysts argue that internalized norms are inherently a-social mechanisms. Therefore, treating such norms as the primary causal mechanism provides a-social or psychological explanations. Rational-actor approaches similarly locate causality within individuals, in this case in an internal process of reason and calculation. Thus, when social network analysts study norms, they are usually not treated as static and internalized but as memes created in response to network positions or that diffuse through social networks (see accounts of adaptation and transmission, below). 
At times, social network-based theories do assume some rationality. However, taking social network positions into account tempers this rationality so it is no longer the dominant causal force. Instead, social network analysts argue that differences in available opportunities mean that uniformly rational actors will make different choices and will experience different consequences even when they make the same choices. Moreover, network positions create obligations and commitments that alter the calculus of rationality by promoting trustworthiness and relieving people of the fear that their interaction partners will always be strictly and ruthlessly rational (Granovetter, 1985; Uzzi, 1996).

Researchers using network structure to explain substantive outcomes frequently combine network-based data with more standard kinds of statistical analyses. By taking networks as the units of analysis, researchers can use statistical methods to determine if more densely interconnected networks provide more support than similarly-sized but more sparsely connected networks (Wellman and Frank, 2001). By taking network positions as the units of analysis, they can ask if people who are in bridges are more likely to be promoted (Burt, 2005). This combined approach is especially common among researchers studying the networks surrounding individual people (see ego networks, below). By sampling unconnected individuals and collecting data about their social networks, researchers can essentially sample networks and network positions. Ego network data for $N$ randomly selected people are essentially data on $N$ randomly selected networks, one ego network for each respondent. The same data could be treated as data on $N$ randomly-selected network positions, using each respondent's position as a unit of analysis (e.g., Wellman, 1979; Fischer, 1982a; Marsden, 1987; McPherson et al., 2006).

\section{Looking at network effects of phenomenon of interest}

Finally, in addition to studying the effects of particular network properties and positions, social network analysts study the causes of networks and positions. For example, McPherson and Smith-Lovin (1987) draw from theories of how foci of social interaction shape social networks (Feld, 1981) to argue that participation in demographically-segregated voluntary associations causes friendship networks to be filled with demographically similar people. Hampton and Wellman (2003) find that within-neighbourhood relations are more likely to form between neighbours who have access to electronic means of communicating with each other. Like researchers studying the effects of network structures, researchers taking this approach also frequently combine network-based data with statistical approaches, taking positions or networks as their units of analysis.

\section{Network Explanations}

In this section, we show how network analysts base their explanations on how particular kinds of networks or network positions can cause particular outcomes. We follow Borgatti et al.'s (2009) classification of network arguments into four categories: transmission, adaptation, binding, and exclusion (see Borgatti, this volume).

\section{Transmission}

Network-based theories frequently treat network ties as pipelines through which many things flow: information about jobs (Granovetter, 1973, 1974), social support (Wellman and Wortley, 1990), norms (Coleman, 1988), workplace identities (Podolny and Baron, 1997), disease 
(Morris, 1993), immunity to disease (Cohen et al., 1997; S. Cohen et al., 2001), material aid (Stack, 1974), or knowledge of culture (Erickson, 1996). Theorists taking this approach study the kinds of networks that result in the most widespread distribution, the network positions most likely to receive flows, and the ways in which different network structures create different patterns of flow under different circumstances. For example, networks leading to people who are neither connected to one another nor connected to the same others provide the best access to new, non-redundant information and ideas (Burt, 1992, 2004, 2005; Hargadon and Sutton, 1997; Granovetter, 1973). On the other hand, networks leading to people who are connected directly to one another transmit consistent expectations and clear norms (Coser, 1975; Coleman, 1988; Podolny and Baron, 1997).

The effects of network structure on the ways in which resources flow through networks may not always be uniform. For example, Bian (1997) finds that where institutional factors make the exercise of influence risky, job opportunities are more likely to flow through strong ties. Gibson (2005a) uses computer simulations to show that having a small number of highly-connected nodes can slow the early stages of diffusion when compared to random networks. However, once central actors have been infected, diffusion rates are comparable.

\section{Adaptation}

Adaptation occurs when two people make the same choices because they have similar network positions and are thus exposed to similar constraints and opportunities. For example, California winemakers make wines from grapes sourced primarily in one region, allowing them to market their wines as Sonoma County or Napa Valley wines. While blending grapes from different sources may create higher-quality wines, losing place-based appellations would lower the status associated with the wine and cause wine drinkers to react similarly - by drinking something else. Therefore, winemakers are not making decisions about how to blend their wines because they are transmitting knowledge of winemaking to one another, but because they are responding to similar network constraints. Maintaining ties to customers requires that they maintain ties with viticultural regions (Podolny, 2005).

\section{Binding}

Binding occurs where a network binds together to act as one unit. The actions or outcomes of that action are influenced by the internal structure of the network. For example, Granovetter (1973) argues that communities fighting urban renewal in their neighbourhoods are better able to organize their resistance when their networks are less fragmented. When community networks are internally disconnected, information cannot diffuse fully through the network and trust in leaders that is facilitated by indirect connections may never develop. With an internally fragmented structure, the community is less effective, less coordinated and more easily defeated in their attempts at collective action than a community with a more integrated network.

\section{Exclusion}

Exclusion occurs when the presence of one tie precludes the existence of another tie, which in turn affects the excluded node's relations with other nodes. This mechanism is most visible in markets or exchange networks where the availability of alternative partners improves a node's bargaining power. A manufacturing firm with two potential suppliers can negotiate a good price 
by creating competition between them. When one of those suppliers enters an exclusive contract with another manufacturer, this not only prevents our protagonist firm from buying from that supplier, but it also greatly increases the remaining supplier's power to name its own price. Similarly, a person with two potential romantic partners loses access to a potential partner who marries someone else. In addition, this person loses bargaining power with the remaining love interest due to the absence of (immediately visible) alternatives.

\section{Studying and Operationalizing Networks}

Although social network analysis is more than a set of algorithms and methods, analysts have developed unique ways of measuring concepts and analyzing relation-based data. These methods have been developed because network analysis' key premise that relations are primary makes it difficult to rely only on analytic tools that treat atomized individuals as primary.

\section{Operationalizing Concepts Relationally}

Studying substantive phenomena from a network perspective requires that at least one theoretically significant concept be defined relationally. This redefinition, together with an examination of its implications, can in itself become a seminal piece of research. However, even where the network definition of a concept is not the primary focus of a project, thinking about how networks cause particular outcomes or what kinds of networks are caused by different forces requires that we map sociological concepts onto particular network forms. For example, we study network density because it is a mathematical expression of concepts such as cohesion, solidarity, or constraint, each of which is associated with social processes likely to have particular effects. For example, cohesion and solidarity create identity (Podolny and Baron, 1997) and reinforce norms (Coleman, 1988; Podolny and Baron, 1997). Constraint (Burt, 1992) is a more negative framing of reinforced norms. We study structural equivalence because it is a mathematical expression of the concept of the role (White et al., 1976; Boorman and White, 1976, Doreian et. al. this volume), and therefore we expect that those who are structurally equivalent will be subject to similar pressures and opportunities.

Similarly, when we study the effects of phenomena on networks, the results are sociologically significant only insofar as the network measures being affected are sociologically significant. If something causes a network to be fractured such that there is no path between pairs of nodes, the fracture matters only because of the social effects it will have. These consequences might include bringing the internet to its knees (R. Cohen et al., 2000, 2001) or preventing the widespread transmission of sexually-transmitted diseases among teenagers (Bearman et al., 2004). Even a measure as basic as the number of ties that particular node has is primarily significant for its social implications: a high level of network activity (Freeman, 1979).

\section{Collecting Network Data}

Researchers collecting network data must first decide what kinds of networks and what kinds of relations they will study. While there are many kinds of network data, we discuss here only two important dimensions along which network data vary: whole vs. ego networks, and one-mode vs. two-mode networks. Researchers must make these choices even before they can begin to think about the boundary specification problem discussed above. 


\section{Whole Networks vs. Ego Networks}

Whole networks take a bird's eye view of social structure, focussing on all nodes rather than privileging the network surrounding any particular node (See Hanneman and Riddle, this volume). These networks begin from a list of included nodes and include data on the presence or absence of relations between every pair of nodes. Two well-known examples are a network where nodes consist of all workers in a factory showing who plays games with whom (Roethlisberger and Dickson, 1939), and a network of actors appearing on film or television showing who has co-starred with whom (Watts, 1999).

Researchers using whole network data frequently analyze more than one relation, sometimes collapsing relations into a single network such as workplace networks or support networks (Burt, 1992; Fischer, 1982a), and sometimes examining how different relations are used to different effect. For example, Padgett (1993) collected data on eight types of relations among elite Florentine families in the fifteenth century to show how the Medici used economic ties to secure political support from geographically neighbouring families, but used marriage and friendship ties with more distant families to build and maintain the family's status.

Egocentric network data focus on the network surrounding one node, known as the ego (see Hanneman and Riddle, this volume). Data are on nodes that share the chosen relation(s) with the ego and on relations between those nodes. Although these networks could extend to the secondorder ego network, nodes sharing relations with nodes related to the ego (e.g., friends of friends), in practice, first-order ego networks are the most commonly studied (e.g., Wellman, 1979; Marsden, 1987; Fischer, 1982a; Campbell and Lee, 1992).

Ego network data can be extracted from whole network data by choosing a focal node and examining only nodes connected to this ego. For example, Burt's $(1992,2005)$ studies of the effects of network constraint are often based on whole network data, though his measure of constraint is egocentric, calculated by treating each node in the whole network as a temporary ego.

Like whole network data, ego network data can also include multiple relations. These relations can be collapsed into single networks, as when ties to people who provide companionship and emotional aid are collapsed into a single support network (Wellman, 1979). Or, each relation can be treated as creating its own network, for example to examine how the kin content of the networks providing material aid differs from the kin content of socializing networks (Wellman and Wortley, 1990). Unlike whole network analyses, which commonly focus on one or a small number of networks, ego network analyses typically sample large numbers of egos and their networks. Typically, these ego networks are treated as the units of analysis using standard statistical methods. In another approach, alters (members of each ego's network) are treated as the units of analysis, using multi-level methods to take into account dependence created by being tied to common egos (Wellman and Frank, 2001; Snijders and Bosker, 1999).

\section{One-Mode vs. Two-Mode Data}

Researchers studying whole networks most frequently collect data on a single type of node in networks where every node could conceivably be connected to any other node. Most of the networks they analyze are one-mode networks. However, some research problems, particularly 
those concerned with group memberships, require the collection and analyses of two kinds of nodes - typically organizations and organization members, or events and attendees. In these twomode networks or affiliation networks, relations consist of things such as memberships or attendance at events that cannot exist between nodes of the same type: A person can attend an event or belong to an organization, but a person cannot attend or belong to another person and an event cannot attend another event (see Borgatti, this volume).

One-mode network data can be derived from two-mode network data by extracting relations that consist of co-membership/co-attendance or relations based on having members of attendees in common (Breiger, 1974). For example, the network of actors who have appeared in movies together (Watts, 1999) is a one-mode network in which nodes are actors and actors are connected to one another if they have both appeared in a movie or television show together. However, this one-mode network is derived from the analysis of a two-mode network in which one mode consists of actors and the second mode consists of movies and television shows.

Types of Ties

Once network types have been chosen and theoretically relevant relations have been identified, researchers must decide how to measure their chosen relations. Relations can be measured as directed or undirected and as binary or valued. Directed ties are those that go from one node to another, while undirected ties exist between two nodes in no particular direction. Adviceseeking, information-sharing, visiting at home, and lending money are directed ties while comemberships are examples of undirected ties. Directed ties may be reciprocated, as would be the case for two people who visit one another, or they may exist in only one direction as when only one gives emotional support to the other (Plickert, Côté and Wellman, 2007). Some kinds of directed ties preclude the possibility of reciprocity: for example, two military officers cannot have command relationships over one another.

Both directed and undirected ties can be measured as binary ties that either exist or do not exist within each dyad, or as valued ties that can be stronger or weaker, transmit more or fewer resources, or have more or less frequent contact. For example, a friendship network can be represented using binary ties that indicate if two people are friends, or using valued ties that assign higher or lower scores based on how close people feel to one another, or how often they interact.

As these examples suggest, decisions about whether to measure ties as directed or undirected or as valued or unvalued are sometimes dictated by the theoretical nature of the tie: a comembership is inherently undirected, and authority is inherently directed. However, for many types of ties, decisions to treat ties as directed or undirected, or binary or valued, are pragmatic choices based on available data, expected methods of analyses, and the expected theoretical payoff.

\section{Survey and Interview Methods}

Network data can be collected through observation (Gibson, 2005b), from archives and historical materials (Gould, 1995; Padgett, 1993), or from trace observation of electronic communications (Carley, 2006). We discuss survey and interview methods here because collecting social network data from network members directly through surveys and interviews involves challenges unique 
to social network data (see Marsden, this volume).

Surveys and interviews collecting social network data ask respondents to report with whom they share particular relations. Collecting whole network data can be done by presenting respondents with a list of network members and asking them to indicate the people with whom they share ties. When networks are too large to make a full list feasible or where no complete list is available, respondents are asked to make a list by recalling the people with whom they share the relevant relation. Follow-up questions may ask respondents to rank the importance or strength of their relation to different network members, to choose their most important relations, or to provide more detail about their relations. Because whole network researchers will also be collecting data directly from other network members, respondents need not report on characteristics of their alters or on relations between the people with whom they share relations. Ego network data is most commonly collected using name generators: survey questions that ask respondents to list the people with whom they share a particular relation (Marsden, 1987; Burt, 1984; Marsden, 2005; Hogan et al., 2007). Because these alters will not be surveyed directly, respondents must report any characteristics of the relationship or characteristics of the alters that are of interest to researchers. Additional data collected from respondents can include information about ties between network members.

These surveys or interviews can be difficult and burdensome for both respondents and researchers. Ego network surveys especially - with their repetitive questions about each alter can be long and boring. In addition, providing the information requested by researchers is difficult. People interpret relations differently (Fischer, 1982b; Bailey and Marsden, 1999; Bearman and Parigi, 2004), they forget people with whom they share relations (Brewer, 2000; Brewer and Webster, 1999; Bernard and Killworth, 1977; Killworth and Benard, 1976; Marin, 2004), they misapprehend relations between their alters (Freeman, 1992), and they may not know their alters' characteristics (Chen, 1999).

Designing surveys and interviews to collect network data presents related issues. Surveys require complicated patterns of skips and loops, with questions not only asked or skipped based on previous answers, but created by incorporating previous responses. Given these challenges, computer-assisted interviewing or computer-based surveying are common (e.g., Hampton, 1999; Marin, 2004; Manfreda et al., 2004 ). However, continued innovation in survey and interview design using non-computer based methods of working around these difficulties shows that the analog interview is not dead yet (Hogan et al., 2007).

When researchers are interested in specific properties of social networks that can be measured without knowing the full structure of the network, they sometimes use data collection methods that collect only relevant data. For example, researchers interested in the diversity of the social status of acquaintances (Lin, 1986; Lin and Erickson, 2008, Erickson, this volume), the size of social networks (Killworth et al., 1990), and resource availability within networks (van der Gaag and Snijders, 2005) have developed specialized measures of data collection.

\section{Analyzing Network Data}

Once network data have been collected, social network analysts use these data to calculate measures of the properties of network positions, dyads, and networks as a whole. Properties of network positions include things such as the number of relations a node has and the extent to 
which the node is a bridge between other nodes (Freeman, 1979). Dyads can vary in the strength or reciprocity of their tie, the similarity of the two nodes (homophily), their content, the number of relation types shared (multiplexity), or the number of communication media used (media multiplexity).

When studying properties of networks as a whole, researchers can look at such things as the proportion of dyads connected to one another (density), the average path length necessary to connect pairs of nodes, the average tie strength, the extent to which the network is dominated by one central actor (centralization [Freeman, 1979]), or the extent to which the network is composed of similar nodes (homogeneity) or nodes with particular characteristics, such as the proportion of network members who are women (composition).

In addition, networks can be studied by the ways that they can be divided into subgraphs. For example, networks may consist of multiple components: sets of nodes that are tied directly or indirectly to one another but are not tied directly to nodes in other components. They may also include cliques, in which every node is tied directly to every other node.

Because social network analysts do not take individuals as their units of analysis, quantitative analyses packages designed for individual- or attribute-based alliances are frequently either unsuitable or intolerably clunky for relation-based analyses. In response to this problem, social network analysts have developed a number of software applications to analyze social network data (see Huisman and van Duijin, this volume). The most commonly used are: Pajek (Batagelj and Mrvar, 2007; Nooy et al., 2005), UCINet (Borgatti et al., 2002), MultiNet (Richards and Seary, 2006), Siena (Snijders, 2001), P*/ERGM (Snijders et al., 2006), R (R Development Core Team, 2007; Butts, 2008), and Node XL (Smith et al., 2009). These packages are designed primarily for the study of whole network data. While egocentric network data can be analyzed using network-specific software packages or standard statistical packages such as SAS, SPSS or Stata (Müller et al., 1999), UCINet also includes functions to calculate egocentric network measures from whole network data.

\section{Applying the Network Perspective Using Qualitative Methods}

Qualitative, as well as quantitative modes of research have been used since the outset of social network analysis (see Hollstein, this volume). Indeed, the earliest social network analyses were qualitative, such as Barnes' study of Norwegian fishing crews (1954) - where he invented the term "social network", Bott's (1957) demonstration that kinship networks trumped social class in explaining English women's domestic behaviour, and Mitchell's (1969) analysis of South African migrants.

More recently, Stack's (1974) ethnography of poor families in a mid-western city defined families relationally as "an organized, durable network of kin and non-kin who interact daily, providing the domestic needs of children and assuring their survival" (p.31). By defining families based on interactions and exchanges rather than on kin-groups or households - two group-based definitions - her research showed the importance of ties across kin groups and households, the ways in which the strength of membership within families varied, with men frequently being less permanently tied than women. It also showed both the fluidity of family memberships - with people sometimes moving between families - and the overlapping nature of families - with people belonging to more than one family group. 
Ethnographers and qualitative interviewers continue to inform their work with network perspectives. For example, Menjívar (2000) uses interviews with Salvadoran immigrants in San Francisco to show how network relations are strained and severed when economic conditions and positions preclude meeting obligations of reciprocity. Domínguez and Maya-Jariego (2008) use ethnographic and interview data to demonstrate that networks connecting immigrants and natives of the host country spread culture in both directions, both assimilating immigrants and causing non-immigrants to adopt aspects of the immigrant culture. In a different vein, Charles Tilly's (1984) lifelong corpus of historical analysis emphasized that contentious politics and social movements drew heavily from the relations among participants.

\section{Conclusions}

Social network analysis is neither a theory nor a methodology. Rather, it is a perspective or a paradigm. It takes as its starting point the premise that social life is created primarily and most importantly by relations and the patterns they form. Unlike a theory, social network analysis provides a way of looking at a problem, but it does not predict what we will see. Social network analysis does not provide a set of premises from which hypotheses or predictions can be derived. The primacy of relations over atomized units has no immediately identifiable specific implications for when inequality will rise or fall, how organizations can ensure success, or who is likely to live a long and healthy life. Taken alone, network analysis can offer only vague answers to these questions: relations within and between classes should matter, relations between organizations should matter, and health-related and -influencing relations will matter. Yet these answers serve a function: While they do not tell social scientists the answers to these questions, they provide guidance on where to look for such answers.

\section{References}

Bailey, Stefanie, and Peter Marsden (1999) 'Interpretation and interview context', Social Networks, 21: 287-309.

Barabasi, Albert-Laszlo and Albert, Reka (1999) 'Emergence of scaling in random networks', Science, 286(5439):509-512.

Barabasi, Albert-Laszlo (2002) Linked. NY: Perseus.

Barnes, J.A. (1954) 'Class and committees in a Norwegian island parish', Human Relations, 7:39-58.

Barnes, J.A. (1972) Social Networks. Reading, MA: Addison-Wesley.

Batagelj Vladimir and Mrvar Andrej (2007) Pajek: Package for Large Network Analysis. University of Ljubljana, Slovenia. http://vlado.fmf.uni-lj.si/pub/networks/pajek/

Bearman, Peter, Moody, James and Stovel, Katherine (2004) 'Chains of affection.' American Journal of Sociology, 110:44-91.

Bearman, Peter S. and Parigi, Paolo (2004) 'Cloning headless frogs and other important matters: Conversation topics and network structure', Social Forces, 83(2):535-557.

Bernard, H. Russell and Killworth, Peter (1977) 'Informant accuracy in social network data II', Human Communication Research, 4:3-18. 
Bian, Yanjie (1997) 'Bringing strong ties back in' American Sociological Review, 62(3):366385.

Blau, Peter M. (1994) Structural Context of Opportunities. Chicago: University of Chicago Press.

Boase, Jeffrey and Wellman, Barry (2006) 'Personal relationships: On and off the Internet', in Anita Vangelisti and Dan Perlman (eds.), CambridgeHandbook of Personal

Relationships.Cambridge: Cambridge University Press. pp. 709-723.

Boorman, Scott, and White, Harrison (1976) 'Social structure from multiple networks II: Role structures', American Journal of Sociology, 81:1384-1446.

Borgatti, Stephen, Everett, Martin and Freeman, Linton (2002) UCINET 6.0 for Windows, , MA: Analytic Technologies. http://www.analytictech.com/

Borgatti, Stephen, Mehra, Ajay, Brass, Daniel and Labianca, Giuseppe (2009) 'Network analysis in the social sciences', Science, 323(5916):892-895.

Bott, Elizabeth (1957) Family and Social Network. London: Tavistock.

Breiger, Ronald (1974) 'The duality of persons and groups', Social Forces, 53:181-190.

Brewer, Devon D. (2000) 'Forgetting in the recall-based elicitation of personal and social networks', Social Networks,22:29-43.

Brewer, Devon and Webster, Cynthia. (1999) 'Forgetting of friends and its effects on measuring friendship networks', Social Networks, 21:361-373.

Buchanan, Mark (2002) Nexus: Small Worlds and the Groundbreaking Theory of Networks. New York: Norton.

Burt, Ronald. (2004) 'Structural holes and good ideas', American Journal of Sociology, 110(2):349-399.

Burt, Ronald (1998) 'The gender of social capital', Rationality and Society, 10:5-46.

Burt, Ronald (1984) 'Network items and the General Social Survey', Social Networks, :293-339.

Burt, Ronald S. (1992) StructuralHoles. Cambridge, MA: Harvard University Press.

Burt, Ronald (1997) 'The contingent value of social capital', Administrative Science Quarterly,42:339-65.

Burt, Ronald (2005) Brokerage and Closure: An Introduction to Social Capital. Oxford: Oxford University Press.

Butts, Carter (2008) 'Network: A package for managing relational data in R', Journal of Statistical Software, 24(2).

Carley, Kathleen M. (2006) 'A dynamic network approach to the assessment of terrorist groups and the impact of alternative courses of action', In Visualising Network Information(pp. KN1-1 KN1-10). Meeting Proceedings RTO-MP-IST-063, Keynote 1. Neuilly-sur-Seine, France. http://www.rto.nato.int/abstracts.asp

Casciaro, Tiziana, Carley, Kathleen M. and Krackhardt, David (1999) 'Positive affectivity and accuracy in social network perception', Motivation and Emotion, 23:285-306. 
Chang, Mariko Lin (2005) 'With a little help from my friends (and my financial planner)', Social Forces, 83(4):1469-97.

Chen, Katherine K. (1999) 'The networks methodology of proxy-reporting: How well do respondents proxy-report different kinds of information on others, and how do respondents err in making these proxy-reports?', Qualifying paper, Department of Sociology, Harvard University, Cambridge, MA.

Cohen, Reuven, Erez, Keren, ben-Avraham, Daniel and Havlin, Shlomo (2000) 'Resilience of the Internet to random breakdowns', Physical Review of Letters, 85:4626-28.

Cohen, Reuven, Erez, Keren, ben-Avraham, Daniel and Havlin, Shlomo (2001) 'Breakdown of the Internet under intentional attack', Physical Review of Letters, 86:3682-85.

Cohen, Sheldon, Brissette, Ian, Skoner, David P., and Doyle, William J. (2001) 'Social integration and health: The case of the common cold', Journal of Social Structure, http://www.library.cmu.edu:7850/JoSS/cohen/cohen.html

Cohen, Sheldon, Doyle, William J., Skoner, David P., Rabin, Bruce S. and Gwaltney, Jack M. (1997) 'Social ties and susceptibility to the common cold', Journal of the American Medical Association, 277:1940-44.

Coleman, James S. (1988) 'Social capital in the creation of human capital', American Journal of Sociology,94:S95-S120.

Coser, Rose Laub (1975) 'The complexity of roles as a seedbed of individual autonomy', The Idea of Social Structure: Papers in Honor of Robert K. Merton, New York: Harcourt Brace Jovanovich.

Campbell, Karen and Lee, Barret (1992) 'Sources of personal neighbor networks: social integration, need, or time?', Social Forces, 70(4):1077-1100.

Domínguez, Silvia and Maya-Jariego, I. (2008) 'Acculturation of host individuals: immigrants and personal networks', American Journal Community Psychology, 42:309-27.

Emirbayer, Mustafa (1997) 'Manifesto for a relational sociology', American Journal of Sociology, 103(2):281-317.

Erickson, Bonnie (1996) 'Culture, class and connections', American Journal of Sociology, 102:217-251.

Feld, Scott (1981) 'The focused organization of social ties”, American Journal of Sociology, 86:1015-35.

Fernandez, Roberto M. and Harris, David (1992) 'Social isolation and the underclass', in Adele Harrell and George Peterson (eds.), Drugs, Crime, and Social Isolation. Washington DC: The Urban Institute. pp. 257-293.

Fischer, Claude S. (1982a) To Dwell Among Friends. Berkeley: University of California Press.

Fischer, Claude S. (1982b) 'What do we mean by friend?', Social Networks,3:287-306.

Fleming, Lee, Marin, Alexandra, McPhie, Jonathan and Colfer, Lyra J. 'Why the Valley went first: Aggregation and emergence in regional collaboration networks', in John Padgett and Walter Powell (eds.), Market Emergence and Transformation. MIT Press, forthcoming. 
Freeman, Linton (1992) 'Filling in the blanks: A theory of cognitive categories and the structure of social affiliation', Social Psychology Quarterly, 55:118-27.

Freeman, Linton (1979) 'Centrality in social networks: Conceptual clarification', Social Networks 1:215-39.

Freeman, Linton, Freeman, Sue and Michaelson, Alaina (1989) 'How humans see social groups: A test of the Sailer-Gaulin models', Journal of Quantitative Anthropology, 1:229-38.

Gibson, David (2005a) 'Concurrency and commitment', Journal of Mathematical Sociology, 29(4):295-323.

Gibson, David (2005b) 'Taking turns and talking ties', American Journal of Sociology, 110(6):1561-97.

Granovetter, Mark (1973) 'The strength of weak ties', American Journal of Sociology, 78:136080 .

Granovetter, Mark (1974) Getting a Job: A Study of Contacts and Careers. Cambridge, MA: Harvard University Press.

Granovetter, Mark (1985) 'Economic action and social structure: The problem of embeddedness', American Journal of Sociology, 91:481-510.

Gould, Roger (1995) Insurgent Identities: Class, Community and Protest in Paris from 1848 to the Commune. Chicago: University of Chicago Press.

Grossetti, Michel (2005) 'Where do social relations come from?' Social Networks, 27:289-300.

Hampton, Keith (1999) 'Computer-assisted interviewing: The design and application of survey software to the Wired Suburb Project', Bulletin de Méthodologie Sociologique, 62:49-68.

Hampton, Keith (2007) 'Neighborhoods in the network society: The e-Neighbors Study', Information, Communication \& Society, 10(5):714-748.

Hampton, Keith and Wellman, Barry (2003) 'Neighboring in Netville', City and Community, 2(3):277-311.

Hargadon, Andrew and Sutton, Robert (1997) 'Technology brokering and innovation in a product development firm', Administrative Science Quarterly, 42:716-749.

Hennig, Marina (2007) 'Re-evaluating the community question from a German perspective', Social Networks, 29(3):375-390.

Hogan, Bernie, Carrasco, Juan-Antonio and Wellman, Barry (2007) 'Visualizing personal networks', Field Methods, 19(2):116-144.

Ibarra, Herminia (1997) 'Paving an alternate route: Gender differences in managerial networks', Social Psychology Quarterly, 60:91-102.

Ibarra, Herminia (1993) 'Personal networks of women and minorities in management', Academy of Management Review, 18:56-87.

Killworth, Peter, and Bernard, H. Russell (1976) 'Informant accuracy in social network data', HumanOrganization, 35:269-86.

Killworth, Peter, Johnsen, Eugene, Bernard, H. Russell, Shelley, Gene Ann and McCarthy, 
Christopher (1990) 'Estimating the size of personal networks', Social Networks, 12:289-312.

Klassen, Sherri. (2008) 'Indicators of research success in sociology at the University of Toronto', [Presentation to the Faculty] Department of Sociology, University of Toronto. Toronto: May 28

Laumann, Edward, Marsden, Peter and Prensky, David (1983) 'The boundary specification problem in network analysis', in Ronald Burt and Michael Minor (eds.), Applied Network Analysis. Beverly Hills, CA: Sage. pp. 18-34.

Lin, Nan (1986) 'Access to occupations through social ties', Social Networks, 8:365-385.

Lin, Nan, and Ensel, Walter (1989) 'Life stress and health', American Sociological Review, 54:382-399.

Lin, Nan and Erickson, Bonnie, eds. (2008) Social Capital. : Oxford University Press.

Manfreda, Katja Lozar, Vehovar, Vasja and Hlebec, Valentina (2004) 'Collecting ego-centred network data via the Web', Metodološki zvezki, 1(2):295-321.

Marin, Alexandra (2004) 'Are respondents more likely to list alters with certain characteristics? Implications for name generator data', Social Networks, 26:289-307.

Marsden, Peter (1987) 'Core discussions networks of Americans', American Sociological Review, 52:122-31.

Marsden, Peter (2005) 'Recent developments in network measurement', in Peter Carrington, John Scott, and Stanley Wasserman (eds.), Models and Methods in Social Network Analysis. Cambridge, UK: Cambridge University Press. pp. 8-30.

Martin, John Levi (2005) 'Is power sexy?', American Journal of Sociology, 111:408-446.

McPherson, J. Miller, and Smith-Lovin, Lynn (1987) 'Homophily in voluntary organizations', American Sociological Review, 52:370-379.

McPherson, J. Miller, Smith-Lovin, Lynn and Brashears, Matthew (2006) 'Social isolation in America', American Sociological Review, 71:353-375.

Menjívar, Cecilia (2000) Fragmented Ties. Berkeley, CA: University of California Press.

Merton, Robert (1968) 'The Matthew Effect in science', Science, 159:56-63.

Mintz, Beth, and Schwartz, Michael (1985) The Power Structure of American Business.

Chicago: University of Chicago Press.

Mitchell, J. Clyde (eds.) (1969) Social Networks in Urban Situations. Manchester: Manchester University Press.

Mizruchi, Mark and Brewster Stearns, Linda (1988) 'A longitudinal study of the formation of interlocking directorates', Administrative Science Quarterly, 33(2):194-210.

Morris, Martina (1993) 'Epidemiology and social networks', Sociological Methods and Research, 22:99-126.

Müller, Christoph, Wellman, Barry and Marin, Alexandra (1999) 'How to use SPSS to study ego-centered networks', Bulletin de Methode Sociologique, 69:83-100.

Nooy, Wouter De, Mrvar, Andrej and Batagelj, Vladimir (2005) Exploratory Social Network 
Analysis With Pajek. Cambridge: Cambridge University Press.

Padgett, John and Ansell, Christopher (1993) 'Robust action and the rise of the Medici, 14001434' American Journal of Sociology, 98(6):1259-1319.

Pescosolido, Bernice (1992) 'Beyond rational choice’, American Journal of Sociology, 97:10961138 .

Plickert, Gabriele, Côté, Rochelle and Wellman, Barry (2007) 'It's not who you know, it's how you know them', Social Networks, 29(3): 405-429.

Podolny, Joel M. (2005) Status Signals. Princeton, NJ: Princeton University Press.

Podolny, Joel M. and Baron, James N. (1997) 'Resources and relationships', American Sociological Review, 62:673-693.

Quan-Haase, Anabel and Wellman, Barry (2006) 'Hyperconnected net work', in Charles Heckscher and Paul Adler (eds.) The Firm as a Collaborative Community.

New York: Oxford University Press. pp. 281-333.

R Development Core Team (2007) R: A language and environment for statistical computing, R Foundation for Statistical Computing, Vienna, Austria. Version 2.6.1, http://www.R-project.org/.

Richards, William and Seary, Andrew (2006) MultiNet for Windows. Version 4.75, http://www.sfu.ca/ richards/Multinet/Pages/multinet.htm.

Roethlisberger, Fritz J. and Dickson, William J. (1939) Management and the Worker. Cambridge, MA: Harvard University Press.

Simmel, Georg (1950) The Sociology of Georg Simmel. Glencoe, IL: Free Press.

Simmel, Georg (1922 [1955]) 'The web of group affiliations', in Kurt Wolff (eds.), Conflict and the Web of Group Affiliations. Glencoe, IL: Free Press. pp. 125-195.

Simmel, Georg (1908 [1971]) On Individuality and Social Forms: Selected Writings. Chicago: University of Chicago Press.

Smith, Marc and the Node XL Development Team (2009) Node XL: Network overview. Version 1.0.1.84, http://www.codeplex.com/NodeXL.

Smith, Sandra Susan (2005) 'Don't put my name on it', American Journal of Sociology, 111:157.

Snijders, T.A.B. (2001) SIENA.Version 3.1, http://stat.gamma.rug.nl/snijders/siena.html. Snijders, Tom and Bosker, Roel J. (1999) Introduction to Multilevel Analysis. London: Sage.

Snijders, Tom, Pattison, Phillippa, Robins, Gary and Handock, Mark (2006) 'New specifications for exponential random graph models', Sociological Methodology, 36:9-153.

Stack, Carol (1974) All Our Kin. New York: Harper \& Row.

Stern, Michael (2008) 'How locality, frequency of communication, and Internet usage affect modes of communication within core social networks', Information, Communication \& Society, 11(5): 591-616.

Tilly, Charles. (1984) Big Structures, Large Processes, Huge Comparisons. New York: Russell 
Sage Foundation.

Uzzi, Brian (1996) 'The sources and consequences of embeddedness for the economic performance of organizations', American Sociological Review, 61:674-98.

van der Gaag, Martin and Snijders, Tom (2005) 'The resource generator', Social Networks, 27:127.

Wasserman, Stanley and Faust, Katherine (1994) Social Network Analysis. Cambridge: Cambridge University Press.

Watts, Duncan (1999) Small Worlds.Princeton, NJ: Princeton University Press.

Watts, Duncan (2003) Six Degrees.New York: Norton.

Watts, Duncan, Dodds, Peter and Newman, Mark. (2002) 'Identity and search in social networks', Science, 296:1302-1305.

Wellman, Barry (1988) 'Structural analysis', in Barry Wellman and S.D. Berkowitz (eds.), Social Structures.Cambridge: Cambridge University Press. pp. 19-61.

Wellman, Barry and Wortley, Scott (1990) 'Different strokes from different folks', American Journal of Sociology, 96(3):558-588.

Wellman, Barry (1979) 'The community question', American Journal of Sociology, 84:12011231 .

Wellman, Barry and Frank, Kenneth (2001) 'Network capital in a multi-level world', in Nan Lin, Karen Cook and Ronald Burt (eds.), Social Capital. Chicago: Aldine DeGruyter. pp. 233-73.

Wellman, Barry and Hogan, Bernie, Berg, Kristen, Boase, Jeffrey, Carrasco, Juan-Antonio, Côté, Rochelle, Kayahara, Jennifer, Kennedy, Tracy and Tran, Phouc (2006) 'Connected Lives: The project' in Patrick Purcell (eds.), Networked Neighbourhoods. Guildford, UK: Springer. pp. 157-211.

White, Howard, Wellman, Barry and Nazer, Nancy (2004) 'Does citation reflect social structure?' Journal of the American Society for Information Science and Technology, 55(2): 111126.

White, Harrison, Boorman, Scott and Breiger, Ronald (1976) 'Social structure from multiple networks: I blockmodels of roles and positions', American Journal of Sociology, 81:730-780.

Wilson, William Julius (1978) The Declining Significance of Race. Chicago: University of Chicago Press.

Wilson, William Julius (1987) The Truly Disadvantaged. Chicago: University of Chicago Press. Zelizer, Viviana A. (1994) The Social Meaning of Money. New York: Basic Books. 